\title{
Using an Interactive Visual Novel to Promote Patient Empowerment through Engagement
}

\author{
Langxuan Yin \\ Northeastern University \\ 360 Huntington Ave, West Village $\mathrm{H}$ \\ Boston, MA 02115 \\ $+1-617-373-4605$ \\ yinlx@ccs.neu.edu
}

\author{
Lazlo Ring \\ Northeastern University \\ 360 Huntington Ave, West Village $\mathrm{H}$ \\ Boston, MA 02115 \\ $+1-617-373-4605$ \\ Iring@ccs.neu.edu
}

\author{
Timothy Bickmore \\ Northeastern University \\ 360 Huntington Ave, West Village $\mathrm{H}$ \\ Boston, MA 02115 \\ $+1-617-373-5477$ \\ bickmore@ccs.neu.edu
}

\begin{abstract}
In this paper we describe a prototype of a serious game designed to improve hospital patients' confidence in managing their hospital stay. We present findings of an evaluation of our visual novel computer game by comparing it with traditional approaches to increasing patient empowerment and patient self-efficacy. The results indicated a significant effect of the type of intervention on improvement in empowerment, but only for participants with gaming experience or who achieved a high level of engagement in the game. This study provides evidence that games may outperform other types of health intervention under certain conditions.
\end{abstract}

\section{Categories and Subject Descriptors}

J.3 [Computer applications]: Life and medical science - Health;

K.8.0 [Personal computing]: General - games.

\section{General Terms}

Design, Experimentation.

\section{Keywords}

Engagement, flow, patient empowerment, serious games, visual novel, self-efficacy.

\section{INTRODUCTION}

Patient empowerment is a capacity-building process whereby individuals increase their belief that they play an active role in their health care, participate in decision-making and manage their care to achieve a greater measure of control over their health and their health care process [5]. It is considered a health enhancing process $[15,29]$, and a lack of power has been deemed as a determinant of ill health [52]. Self-efficacy is a concept closely related to patient empowerment. The term was coined in the 1970s by Bandura, defined as an individual's belief of having the capacity to organize and execute the courses of action required to produce given attainments $[8,11]$. Self-efficacy affects how well

Permission to make digital or hard copies of all or part of this work for personal or classroom use is granted without fee provided that copies are not made or distributed for profit or commercial advantage and that copies bear this notice and the full citation on the first page. To copy otherwise, or republish, to post on servers or to redistribute to lists, requires prior specific permission and/or a fee.

FDG '12, May 29-June 1, 2012, Raleigh, NC, USA.

Copyright (C) 2012 ACM 978-1-4503-1333-9/12/05 ...\$10.00. individuals perform on a task, how much effort they are willing to expend on it, and how much stress they experience [32]. Those low in self-efficacy on a certain task imagine difficulties as more formidable than they really are and become stressed out by their own imaginations $[14,34]$. These doubts tend to hinder their efforts or make them give up altogether, whereas a strong sense of self-efficacy helps a person master the challenges [12, 19, 47, 53]. Judgments of self-efficacy come from four principal sources of information: 1) enactive attainments, an individual's historical personal experiences; 2) vicarious experiences, the observations of successes and failures of similar others; 3) verbal persuasion, persuasive arguments to make an individual believe whether or not they possess capabilities to achieve a goal; and 4) physiological state, where people learn by reading their own visceral arousal in stressful and taxing situations. Amongst all the four information sources, enactive attainment has proven to be the most influential [9].

In health care, the connection between patient empowerment processes and self-efficacy has been studied for decades, and research findings show that when patients become empowered, they develop a greater sense of self-efficacy regarding disease and treatment-related behaviors (e.g. asking questions) [7]. As a result, researchers in health care commonly use self-efficacy to measure the outcomes of patient empowerment interventions $[6,30,38,44$, 51].

Patient empowerment is a highly interactive process that requires communication and education in which knowledge, values and power are shared [5]. In the health care domain, a few games have shown promising outcomes in terms of their players' self-efficacy in certain areas such as sexual behavior and diabetes $[20,50]$. However, whether games yield similar outcomes in hospital patient empowerment interventions has not yet been studied.

One traditional approach to patient empowerment is to support the patients' autonomy and actively encourage them to participate in consultations with healthcare providers (e.g. by asking questions) and taking a more active role in making health-related decisions [5]. These have been shown to contribute not only to the patients' self-efficacy, but also to the improvement of their health condition in general $[36,39,43,45]$. In an experiment conducted by Langer \& Rodin [33, 46], patients in a nursing home were given the responsibility to decide on details of their daily lives, and were asked to give suggestions on changes to the staff as well as to take care of a houseplant. Compared to patients in the control group, these responsibility-induced patients became happier, healthier, more active, and more alert by the end of the intervention. 
In this paper, we present a computer game designed to promote patient empowerment, "The Time Mage", where the players are to interact with non-player characters in a virtual hospital environment to help a patient character recover from a heart attack. Through storytelling, we aim to support the player's autonomy, guide their participation in the health care system, and help them take responsibility not only for themselves, but also for a virtual patient.

The game takes on the form of a visual novel, which is a genre of games similar to interactive fiction [41], but with the addition of static images and animations to help players better visualize the story being told. We chose this genre for several reasons. First, the visual novel's low demand on player actions serves to keep its player's anxiety level low, making it appropriate for hospital. Second, the genre's dependence on storytelling gives it the potential for long-term episodic interventions. And third, the roleplaying element provides the player with an experience that may actually provide enactive attainment to increase self-efficacy.

In this work, we describe the design of a prototype of this game and discuss the results of a preliminary experiment that tested the prototype's impact on its players.

\section{RELATED WORK}

\subsection{Games for Health}

There are now many serious games developed as health interventions, a number of which have been demonstrated to be efficacious $[2,4,13,21]$. The majority of these games are focused on helping players gain more knowledge about certain ailments or their health conditions. Amongst these, Reach Out! Central is a game similar to our approach, which is a visual novel that integrated elaborated storytelling into game play to help teenagers cope with bullying, bad temper, and other behavioral problems [21].

A handful of games are particularly relevant to patient empowerment, focusing on improving the player's health related self-efficacy. Life Challenge, developed by Thomas et al., allows players to role-play with imaginary partners at different points of time. Studies on the game have shown significant outcomes in terms of player learning and self-efficacy towards HIV/AIDS prevention [50]. Packy \& Marlon is a video game on Super Nintendo aimed at improving self-care among children and adolescents with diabetes. The game play includes role-playing two elephants with diabetes to clear out a gang of rats that stole their food and medical supplies. An evaluation of Packy \& Marlon conducted by Brown et al. showed significant improvements in participants' self-efficacy related to diabetes [20]. This game and two others, Bronkie and Rex Ronan, were evaluated in another study [35]. However, these findings have yet to be validated in a clinical setting or compared to alternative or traditional approaches.

Within the hospital setting, the most related work is the Zora virtual community. The systems created by Bers et al. to help pediatric hospital patients gain support and get involved in meaningful activities, allowing the users to build virtual rooms and populate them with objects and characters representing aspects of themselves [17]. Preliminary studies of Zora have shown positive feedback from its young users [16]

\subsection{Visual Novels}

According to Wikipedia, the visual novel that is considered to have defined the genre is The Portopia Serial Murder Case [3], published in Japan in 1983, where the players search for clues, interact with non-player characters and piece together evidence to solve a murder puzzle. Ace Attorney, also developed in Japan, has become a popular series both in Asia and in the US since the first release in 2001. Each game in the series has several cases that the player has to solve, most of the time defending a client as a lawyer. In each case, the player typically investigates crime scenes, collects evidence, and proves the accuser wrong. Compared to The Portopia Serial Murder Case, which featured a verb-noun parser to process player input, Ace Attorney limited player input to two to four options, and employed a more linear storytelling. Ace Attorney has also seen major advances in graphics and the use of animation. Myst, published in 1993, is probably the best known commercial visual novel developed in the US. The game features a player character referred to as the Stranger and a mysterious island for the player to explore by dragging objects and clicking on places in each scene.

In academia, despite the inclusion of real-time rendered animation and natural language recognition, Mateas' interactive game Façade [37] can still be categorized as a visual novel. Whether Façade is a successful game experience has long been a topic of debate [26-27, 31, 40], but researchers argued an interactive story can indeed be highly engaging to game players, leading to what Dow referred to as the "embodied narrative engagement" [27].

\section{PROTOTYPE DESIGN}

In order to test the idea of enhancing patient empowerment using a visual novel, we developed a prototype of the game containing the first chapter of the storyline to support a pilot study.

\subsection{Story}

"The Time Mage" features a story where the player character, often referred to as the Time Mage for his/her supernatural power of time travel, goes back in time to save his/her dearest family member from a fatal heart attack. The player is frequently asked to decide what to do and what to say, and is given two to four choices at each input opportunity. Besides the player character, the first chapter of the story features four other characters:

Aron Archer: An old man that raised the player character from a child, whom the player character considers a brother. $\mathrm{He}$ is depicted as a brave man and the leader of "The Organization", a company whose purpose is not revealed within the story.

Duran: Aron's assistant in "The Organization".

Les Green: Aron's attending physician at Zeit Hospital.

Chelsea: Head nurse at Zeit Hospital.

Figure 1 depicts the stream of the story, marked by various checkpoints where the player is asked to make critical choices.

The story begins with the player character standing in front of Aron, who now has to spend his life bedridden (marked as Undesired Future in Figure 1). The player character regrets that he/she was not by Aron's side when he had a heart attack, and so he/she decides to use time travel to go back to when Aron entered the hospital (marked as Beginning). Once in the hospital, Aron holds the player character's hand and whispers his/her name, where the player is asked to type in their real name. Duran then 


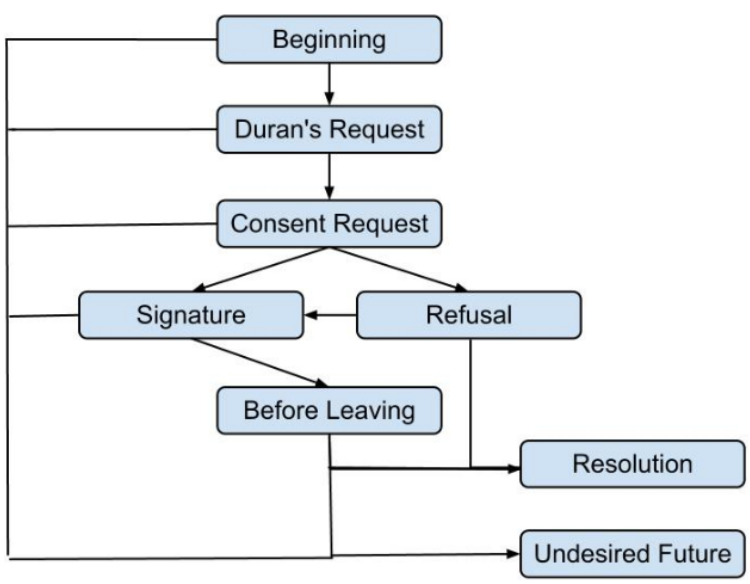

Figure 1. Stream and Checkpoints of "The Time Mage"

asks the player to take charge of Aron's hospital stay, so he can take care of "The Organization" during Aron's absence (marked as Duran's Request). The player then meets Chelsea, who informs the player that Doctor Les Green will request a signature for Aron's angioplasty consent form.

When Les shows up and requests the player's signature (marked as Consent Request), the player can choose to ask what an angioplasty is, read the consent form thoroughly, agree to sign, or refuse to sign. At this point, the player character will realize that what is presented is an arthroplasty consent form, instead of an angioplasty consent form (angioplasty and arthroplasty are two entirely different procedures).

If the player refuses to sign (marked as Refusal), they may demand that Les Green correct the mistake and present the correct form. If the player agrees to sign the consent (marked as Signature) under the doctor's pressure, Chelsea will later inform the player character again that arthroplasty is to be performed on Aron before the player character is asked to leave the emergency room (marked as Before Leaving). At this point the player may request again that the mistake be corrected.

The player is allowed to go back to any checkpoint marked in Figure 1 if they reach a point in the story where they cannot correct the mistake, described in the story as the player character using time travel. The player will eventually reach the end of the story by following the correct path, where the correct surgery is performed (marked as Resolution).

\subsection{Design for Flow}

We hypothesize that games may outperform other media for promoting patient empowerment because they promote engagement - both longitudinally (via retention and use) and during any given moment of gameplay (via cognitive engagement). To maximize the engagement, we look at flow, a concept that encompasses the former.

Flow was first defined by Csikszentmihalyi in the 1970s to describe an optimal experience that is intrinsically rewarding, or autotelic [22-23]. In the past decade, flow has also been found to encompass aspects critical to games including engagement and immersion. In a framework that Brown and Cairns proposed to understand game immersion, the three stages of immersion- engagement, engrossment, and total immersion-all reflect certain aspects of the flow state [18]. Douglas also argued that flow is a state where "both engagement and immersion" occur [25]. Despite the vague definition of these game-related terms, we decided to use flow as our objective to maximize engagement in the game because of the recognized correlation between these concepts.

The storyline and player choices are designed in such a way as to maximize flow. We paid attention to three sub-dimensions of flow that can be controlled at design time: challenge-skill balance, clear goals, and unambiguous feedback. First, the player is challenged to make sure Aron survives the surgery, yet they are given more than one chance to correct the mistake in the consent form in a single game play. Even if the player fails to take the last chance, they're allowed to go back to any checkpoint and start over. This way, challenge-skill balance is achieved. Second, the player is given a clear goal of saving Aron Archer's life from the beginning of the game. Third, the player receives clear feedback by music shift and character reactions as to whether their choices are leading to good or bad outcomes. Last but not least, the player is given options at almost any time they're asked to make a choice, be it to say something, or to do something, thus the player is given a sense of control. [24]

\subsection{Design for Patient Empowerment}

We made several design decisions with the game's ultimate application in the hospital in mind. Because the target player audience of the game is hospital patients who may be feeling scared and anxious about their situation, we decided not to put players in the role of a patient in the game. Instead, the player is expected to take care of a patient, the empowering effect of which has been implied in Langer \& Rodin's work [33, 46]. However, we did set the game scenario in a virtual hospital, since this gives the player an opportunity to actually understand how things work in hospitals, which allows for an experience close to an enactive attainment in Bandura's self-efficacy theory. In addition, the story is kept to a low intensity and has a heavy emphasis on the process to deal with the mistake on the consent form, because we want a patient to stay calm for most of the game play and to focus more on the hospital experience compared to the rest of the story. The game also used recorded narration from four voice actors in addition to text in order to both increase engagement and to accommodate patients with limited literacy. Human narrators also provide a higher quality soundtrack than a text-to-speech engine.

\subsection{Development}

The game prototype was built upon an interactive state machine. The run time application used for our system was a light weight interpreter for the states, implemented in Adobe's Flash and Action Script 3.0.

For the actual game logic, an XML-based state language was created. The states consist of a main XML element, State, with various children elements that allow the story writer to manipulate the scene. These manipulations include the ability to load external animations or artwork, playback multiple audio files at a time, and request either text based or menu input from the user.

Each character in the game was voiced by a separate voice actor, except for Aron Archer, who doesn't say a word throughout the entire game besides whispering the player's real name, and the protagonist, "The Time Mage", who is controlled by the player. 
A group of nurses show up around the corner, one of them glancing at you as they are approaching the emergency room. She is wearing a badge. You can't quite read it, but she seems to be the head nurse.

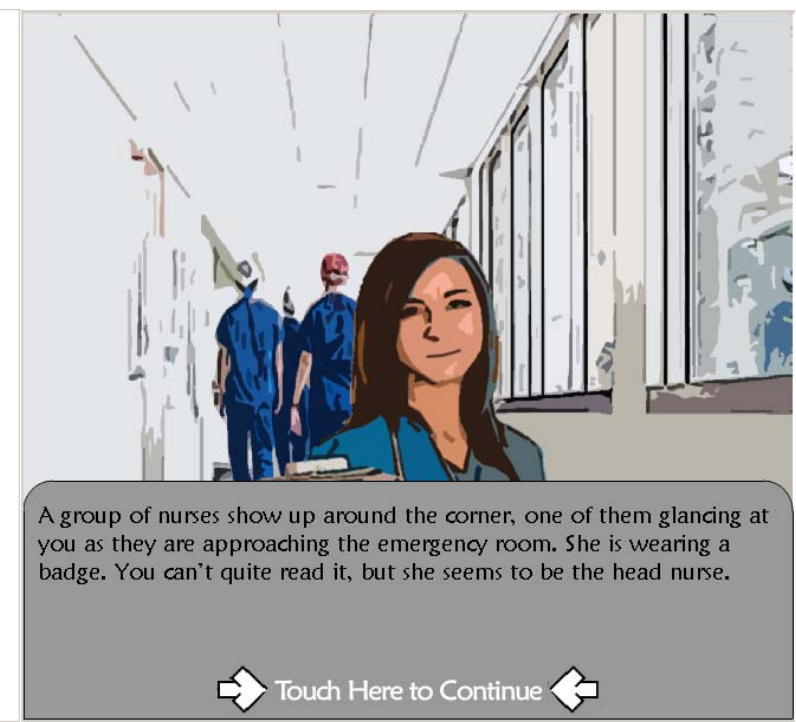

Touch Here To Continue

Figure 2. Screenshots of the Novel condition (left) and the Game condition (right).

Art in the prototype consists of internet photos modified to create cartoon style pictures. Background music was selected from various sources. Duran, Les Green and Chelsea each have their own theme music. During the game play, each time the mood of the game changes, the music is also switched to reflect this change.

\section{EVALUATION}

\subsection{Study Design}

In order to test the impact of the prototype on its players, we conducted a lab study. The experiment is a between-subject design, and has three conditions: 1) a Control condition where the participant is asked to read through the Patient Rights and Responsibilities of Boston Medical Center (a paper pamphlet) [1]; 2) a Novel condition where the participant is asked to go through "The Time Mage" in the form of a novel on a computer, with no audio or artwork, where the participant has no control over the story, and 3) a Game condition where the participant is presented with "The Time Mage" in the form of a visual novel game. The script in the Novel condition follows the longest path of the storyline, where the main character succumbs to Doctor Green's request of an arthroplasty consent, but later manages to correct the mistake by mentioning it to Chelsea. Figure 2 shows screenshots of the Novel and Game conditions. Participants are left alone in the experiment room during the intervention in all conditions. In both the Novel and the Game conditions, the participant is asked to use a touch screen computer for the intervention.

Dependent variables include the participant's engagement in the intervention and their change in self-efficacy [10], i.e. confidence, in solving problems during a hospital stay before and after the intervention (Figure 3).

Based on the above discussion, we hypothesize that:

H1: Participants in the Game condition will have a significantly higher increase in self-efficacy in taking care of themselves during a hospital stay compared to the other two conditions.

Also, because individuals in a flow state experience a high level of challenge which matches their level of skill, we expect participants in a flow state during the intervention will have a higher increase in their self-efficacy. Since the flow state is measured with a continuous score in this study, we have the following hypothesis:

H2: Participants with a higher flow score will have a significantly higher increase in self-efficacy in taking care of themselves

I. I can always manage to solve difficult problems encountered in the hospital if I try hard enough.

2. If a health provider opposes me, I can find the means and ways to get what I want.

3. I am certain that I can accomplish my goals during my hospital stay.

4. I am confident that I could deal efficiently with unexpected events in the hospital.

5. Thanks to my resourcefulness, I can handle unforeseen situations during my hospital stay.

6. I can solve most problems in the hospital if I invest the necessary effort.

7. I can remain calm when facing difficulties in the hospital because I can rely on my coping abilities.

8. When I am confronted with a problem in the hospital, I can find several solutions.

9. If I'm in trouble during my hospital stay, I can think of a good solution.

10. I can handle whatever comes my way during my hospital stay.

Figure 3. Questions in the modified Generalized Self-Efficacy Scale for taking care of oneself. Participants are asked to rate on a 7-point likert scale whether each question reflects their opinion. 
during a hospital stay compared to those with a lower flow score.

\subsection{Measures}

Socio-demographics were measured at the beginning of the experiment for each participant, and included sex, age, experience with computers, experience with games, attitude towards computers, attitude towards games, and the genres of video game that they prefer. These were used for post hoc analyses.

The English version of the Generalized Self-Efficacy Scale [48] was modified to measure 1) the participant's confidence in taking care of themselves during a hospital stay (Figure 3) as well as 2) their confidence in taking care of a family or friend during their hospital stay. These two questionnaires were administered both before and after the intervention in every condition.

The Flow State Scale was used as a measure of flow [28]. Nine subscales were measured each representing one of the nine dimensions of flow. The scores of these subscales would then be summed up to generate a composite score of flow. Participants were asked how much time they spent on the intervention. The actual time spent on the intervention would be recorded and the difference between the time spent and the participant's estimate of time spent would be calculated as an additional measure of transformation of time.

In order to inform further development of the game, a semistructured interview was also conducted at the end of the study in the Novel and Game conditions regarding the participant's impressions of the story and the characters.

\subsection{Participants}

Participants were recruited via fliers and advertisements on the internet. Participants were enrolled if they were 18 years old or older, speak and read English, and have been hospitalized before or have accompanied someone who was hospitalized.

Thirty-six participants were recruited for the study, 21 females and 15 males. Participants' age ranged from 19 to 64 . In terms of education, one participant went to some high school, one was a high school graduate or GED, 11 participants went to some college, 14 were college graduates, and the other 9 were advanced

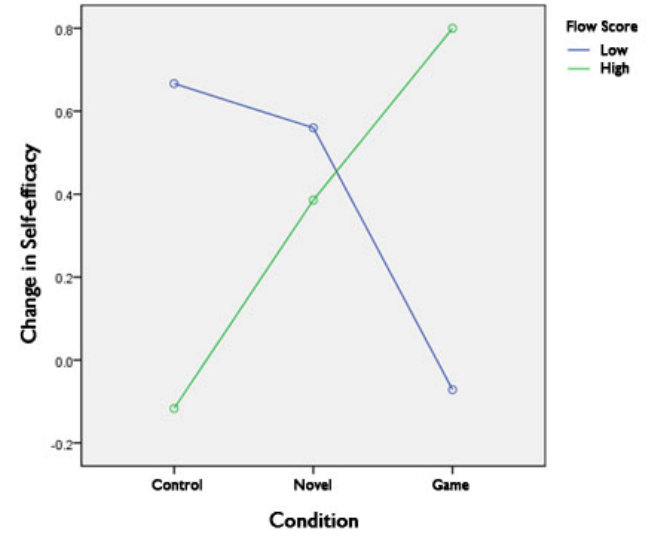

Figure 4. Interaction effect of study condition and flow on change of self-efficacy, $F(2,33)=6.886, p=.003$. . Flow state score is split at the median and categorized into High and Low for this plot.

degree holders.

\subsection{Results}

The 10-item modified self-efficacy questionnaires are found to be highly reliable. Based on the results from this study, Cronbach's alphas for the four measurements are the following: self-efficacy for the self pretest: $\alpha=.869$, self-efficacy for the self posttest: $\alpha=$ .898 , self-efficacy for the other pretest: $\alpha=.904$, self-efficacy for the other posttest: $\alpha=.917$.

To test our hypothesis H1, we analyzed the data with an ANOVA, using the condition as an independent variable and the change in self-efficacy (post-score minus pre-score) as a dependent variable. The test showed no significance, $\mathrm{F}(2,33)=0.319$, n.s.

To test our hypothesis $\mathrm{H} 2$, we tested the Pearson correlation between composite flow score and change in self-efficacy. The test also showed no significance, $r=.108$, n.s.
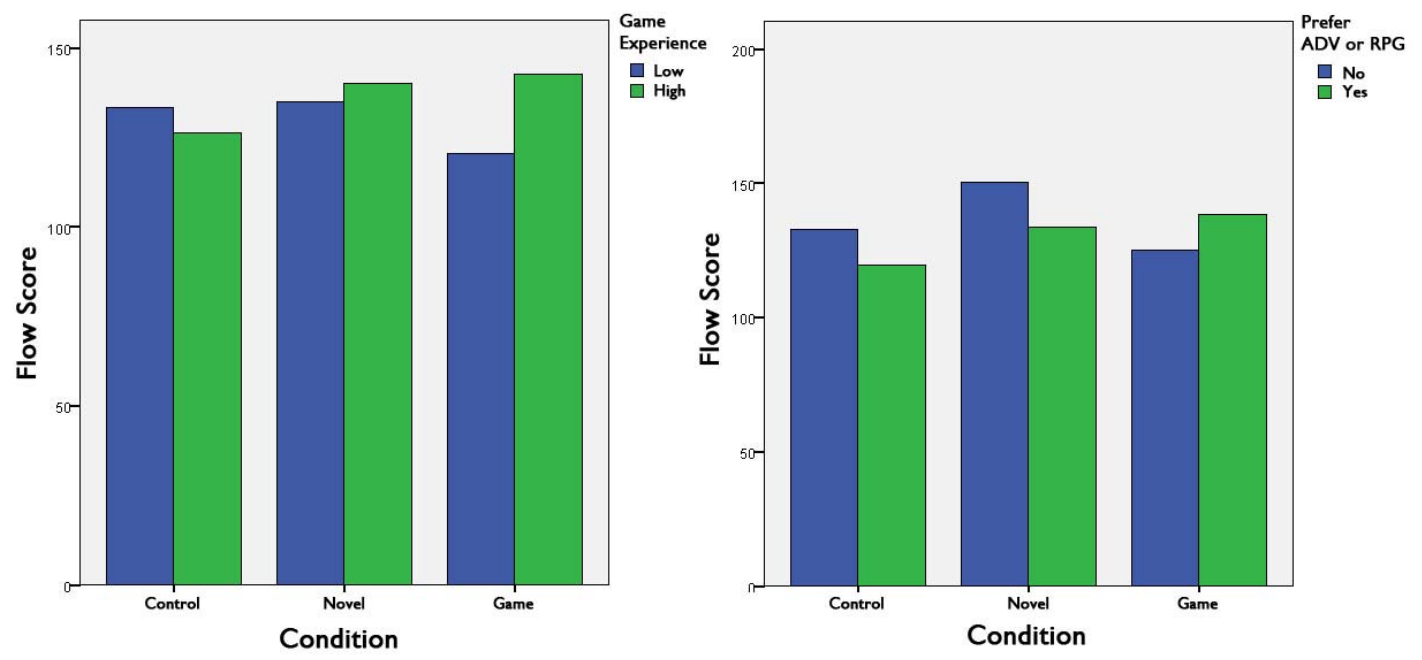

Figure 5. The interaction effect of study condition and game experience on flow (left), $F(5,30)=3.088, p=.060$, and the interaction effect of study condition and game genre preference on flow (right), $F(5,30)=3.03, p=.063$. 


\subsubsection{Exploratory Analysis}

To test whether the type of intervention and flow have any interaction effect, we analyzed the data with an ANCOVA, using the study condition as an independent variable, the composite flow score as a covariate, and the change in self-efficacy as a dependent variable. Under this model, the study condition has a significant impact on the change of self-efficacy, $\mathrm{F}(2,33)=$ $6.865, \mathrm{p}=.004$. The study condition and the flow score also have a significant interaction effect on the change in self-efficacy, $\mathrm{F}(2$, $33)=6.886, p=.003$. Figure 4 is a plot showing the trend revealed by this analysis.

To test whether game experience influences a participant's engagement in the game, we divided the participants into two categories: gamers who, on a scale of 1 to 4 , rated 3 or 4 in terms of game experience in the sociodemographics questionnaire (they play games regularly or deem themselves as experts), and nongamers who rated 1 or 2 for this question (they never played or tried one a few times). An ANOVA shows that the interaction of study condition and game experience has a near significant impact on flow, $\mathrm{F}(5,30)=3.088, \mathrm{p}=.060$. Gamers tend to have a higher flow state score in the Game condition than non-gamers, whereas non-gamers fare better on this score in the other two conditions. Participants who like role-playing games and/or adventure games also appear to have a higher flow state score in the Game condition compared to those who like neither, and an ANOVA shows near significance on this impact, $F(5,30)=3.03, p=.063$. Figure 5 demonstrates these two effects.

ANCOVAs using the study condition as an independent variable and the change in self-efficacy as a dependent variable, with the subscales of the Flow State Scale as covariates show that the study condition has a significant interaction effect with the clear goals subscale of the Flow State Scale $[F(2,33)=6.665, p=$ $.004]$, and a near significant interaction effect with the autotelic experience subscale $[\mathrm{F}(2,33)=2.944, \mathrm{p}=.068]$ on change in self-efficacy: participants who rated higher in clear goals and autotelic experience had a higher increase in self-efficacy.

\subsubsection{Qualitative Results}

We analyzed the audio-recorded interviews in the Novel and Game conditions. We only discuss our findings briefly due to space limitations.

When asked to describe "your own role" in the story, while two out of twelve participants in the Novel condition felt the Time Mage was being responsible, four participants expressed the feeling that the character had no control over the problem posed in the story, whereas four out of twelve participants in the Game condition sensed themselves as being "in control", "important" and "empowered". Some participants in the Novel condition have also expressed that they did not agree with what the "Time Mage" did in the story, and they would have taken a different path if given the chance. Yet in the Game condition, a participant mentioned that she managed to do what she wasn't able to in real life:

“During my hospital stay, I didn't feel like I was in control... this (the game) was kind of an interesting experience to understand that... I feel empowered. I like that."

---- Participant 30

\section{Discussions}

Our findings suggest that change in self-efficacy is influenced by both the type of intervention and the achievement of the flow state.

In the Game condition, the higher the flow score, the more increase in self-efficacy. Because flow is considered a postcondition and an encompassing concept of many constructs, including engagement and immersion [18, 42, 49], this means that the more a player becomes engaged in the game, the more confidence they gain. Playing the game allows the participant to virtually experience solving problems during a hospital stay in person, which provides the participant with an opportunity to experience an enactive attainment in Bandura's terms [9]. However, if the game is not engaging to a player, the game experience fails to become an enactive attainment for them, and hence success or failure in the game will not influence their change in self-efficacy.

Interestingly, this trend is reversed in the Control condition. Our conjecture is that those who achieved a higher flow score reading the Patient's Rights and Responsibilities brochure became anxious when faced with challenges in the hospital, even hypothetically, which lowers their self-efficacy in actually taking care of themselves. We would like to discuss a few concepts related to flow here: anxiety, boredom, challenge and skills. Anxiety is described as the state where challenge of an activity exceeds its participant's skill level, boredom is the state where the participant's skill level exceeds the activity's challenge, and flow lies in between, where the challenge matches the participant's skill level [24]. Following our conjecture, those with a high flow score in the Control condition had skills matching the challenge of reading the Patient's Rights and Responsibilities. However, taking care of oneself in the hospital is more challenging than reading the document to know what one's rights and responsibilities are. This raise of challenge may have made these participants anxious, and this anxiety is reflected on their selfefficacy as a low post-score.

Our results also indicate that participants with more game experience and those who claim to prefer role-playing games and adventure games tend to better enjoy the game. We tested roleplaying game and adventure game preference because these two types of games are usually heavy on storytelling, and "The Time Mage" is indeed a game of storytelling. Game experience and genre preference may be critical factors in determining how much benefit a player will gain from playing the game, although a model involving such factors in addition to study condition, flow and self-efficacy is too complicated to test in the current study.

\section{Future Work}

Because our ultimate goal is to use games for patient empowerment in a hospital setting, making health care a more enjoyable experience, we want to find out how to make a wider range of hospital patients more engaged in the game so as to improve the practical outcomes. If game experience truly influences a player's change in self-efficacy, the question still remains how to make a non-gamer's game experience more enjoyable so that they can benefit from games too. We're also curious to see if the impact of genre preference is universal, i.e. whether a player who prefers action games, for example, will have a significantly better self-efficacy after playing an action game. Nevertheless, storytelling is efficient in the delivery of meaning. It could be that visual novels are particularly effective 
for educational purposes compared to other genres, and that the participants who prefer role-playing games and adventure games just happen to best accept the meaning delivered. We decided to use visual novel based on our beliefs regarding this genre. These beliefs are yet to be tested as well.

Results related to character believability and the player's perceptions of each character are not discussed in this paper. These results show that players have mixed feelings about the characters, but teasing out significant results for each character is beyond the scope of this paper. One step in the near future, however, is to study the inference we can draw from players' thoughts of these characters as well as their own character.

We also hypothesize that a fully developed storyline will yield better outcomes compared to the current prototype, especially if played over a period of several days. Thus we want to find out how participants will react differently to a complete multi-chapter storytelling of "The Time Mage". Finally, we plan to evaluate the game in the hospital setting with real hospitalized patients.

\section{ACKNOWLEDGMENTS}

We would like to thank Laura Vardoulakis and Daniel Schulman for constant inspiring discussions throughout the development and the evaluation of the game. We want to thank Juan Fernandez for his experience in visual novels that broadened our scope of knowledge in the genre. We would also like to thank Michael Paasche-Orlow and his group at the Boston Medical Center for their input to the game as physicians and medical researchers, as well as Magy Seif El-Nasr for her insightful recommendations to improve the paper. We're also grateful for the support of all the members in the Relational Agents Group at Northeastern University.

\section{REFERENCES}

1. Boston Medical Center Patient Rights and Responsibilities. http://www.bmc.org/Documents/bmcPatientRights-english.pdf

2. Escape From Diab.
3. The Portopia Serial Murder Case. http://en.wikipedia.org/wiki/The_Portopia_Serial_Murder Case

4. Replay: Finding Zoe. http://www.metrac.org/replay/index.html

5. M. Alegría, A. Polo, S. Gao, L. Santana, D. Rothstein, A. Jimenez, M. Hunter, F. Mendieta, V. Oddo, S. Normand: Evaluation of a patient activation and empowerment intervention in mental health care. Medical care 46, 247 (2008)

6. R.M. Anderson, M.M. Funnell, P.M. Butler, M. Arnold, J. Fitzgerald, C. Feste: Patient empowerment. Results of a randomized controlled trial. Diabetes Care 18, 943 (1995)

7. I. Aujoulat, W. d'Hoore, A. Deccache: Patient empowerment in theory and practice: polysemy or cacophony? Patient education and counseling 66, 13-20 (2007)
8. A. Bandura: Self-efficacy: toward a unifying theory of behavioral change. Psychological review 84, 191 (1977)

9. A. Bandura: Self-efficacy mechanism in human agency. American psychologist 37, 122 (1982)

10. A. Bandura: Social foundations of thought and action: A social cognitive theory. Changes 1, (1986)

11. A. Bandura: Self-efficacy: The exercise of control. Worth Publishers (1997)

12. A. Bandura, D.H. Schunk: Cultivating competence, self-efficacy, and intrinsic interest through proximal self-motivation. Journal of Personality and Social Psychology 41, 586 (1981)

13. I. Beale, P. Kato, V. Marin-Bowling, N. Guthrie, S. Cole: Improvement in cancer-related knowledge following use of a psychoeducational video game for adolescents and young adults with cancer. Journal of Adolescent Health 41, 263-270 (2007)

14. A.T. Beck: Cognitive therapy and the emotional disorders. (1976)

15. L.J. Bergsma: Empowerment education. American Behavioral Scientist 48, 152 (2004)

16. M. Bers, C. Chau, K. Satoh, L. Beals: Virtual communities of care: Online peer networks with post-organ transplant youth. 78-80 (2007)

17. M.U. Bers, J. Gonzalez-Heydrich, D. Raches, D.R. DeMaso: Zora: a pilot virtual community in the pediatric dialysis unit. Studies in health technology and informatics 800-804 (2001)

18. E. Brown, P. Cairns: A grounded investigation of game immersion. CHI '04 extended abstracts on Human factors in computing, pp. 1297-1300. ACM, (2004)

19. I. Brown, D.K. Inouye: Learned helplessness through modeling: The role of perceived similarity in competence. Journal of Personality and Social Psychology 36, 900 (1978)

20. S. Brown, D.A. Lieberman, B. Gemeny, Y. Fan, D. Wilson, D. Pasta: Educational video game for juvenile diabetes: results of a controlled trial. Informatics for Health and Social Care 22, 77-89 (1997)

21. J. Burns, C. Morey, A. Lagelée, A. Mackenzie, J. Nicholas: Reach Out! Innovation in service delivery. Medical Journal of Australia 187, 31-34 (2007)

22. M. Csikszentmihalyi: Flow: Studies of enjoyment. University of Chicago (1974)

23. M. Csikszentmihalyi: Play and intrinsic rewards. Journal of Humanistic Psychology (1975)

24. M. Csikszentmihalyi: Flow: The psychology of optimal experience: Steps toward enhancing the quality of life. Harper Collins Publishers (1991)

25. Y. Douglas, A. Hargadon: The pleasure principle: immersion, engagement, flow. Proceedings of the eleventh ACM on Hypertext and hypermedia, pp. 153-160. ACM, (2000)

26. S. Dow, M. Mehta, E. Harmon, B. MacIntyre, M. Mateas: Presence and engagement in an interactive drama. 
Proceedings of the SIGCHI conference on Human factors in computing systems, pp. 1475-1484. ACM, (2007)

27. S.P. Dow: Understanding user engagement in immersive and interactive stories. Georgia Institute of Technology (2008)

28. S.A. Jackson, H. Marsh: Development and validation of a scale to measure optimal experience: The Flow State Scale. Journal of Sport \& Exercise Psychology (1996)

$29 . \quad$ P.S. Jones, A.I. Meleis: Health is empowerment. Advances in nursing science (1993)

30. J. Kidd, T.M. Marteau, S. Robinson, O.C. Ukoumunne, C. Tydeman: Promoting patient participation in consultations: a randomised controlled trial to evaluate the effectiveness of three patient-focused interventions. Patient education and counseling 52, 107-112 (2004)

31. R.L. Knickmeyer, M. Mateas: Preliminary evaluation of the interactive drama facade. Proceedings of the SIGCHI conference on Human factors in computing systems, pp. 1549-1552. ACM, (2007)

32. M. Korcok: Health information industry: pushing patient education. Canadian Medical Association Journal 129, 172 (1983)

33. E. Langer, J. Rodin: The effects of choice and enhanced personal responsibility for the aged: A field experiment in an institutional setting. The interface of social and clinical psychology: key readings 339 (2004)

34. R.S. Lazarus, R. Launier: Stress-related transactions between person and environment. Perspectives in interactional psychology 287, 327 (1978)

35. D.A. Lieberman: Management of chronic pediatric diseases with interactive health games: Theory and research findings. The Journal of Ambulatory Care Management 24, 26 (2001)

36. S. Maliski, B. Clerkin, M. Litwin: Describing a nurse case manager intervention to empower low-income men with prostate cancer. Oncology nursing forum 31, 5764 (2004)

37. M. Mateas: Interactive drama, art and artificial intelligence. Carnegie Mellon University (2002)

38. S. McCann, J. Weinman: Empowering the patient in the consultation: a pilot study. Patient education and counseling 27, 227-234 (1996)

39. C. McWilliam, M. Stewart, J. Brown, S. McNair, K. Desai, M. Patterson, N. Del Maestro, B. Pittman: Creating empowering meaning: an interactive process of promoting health with chronically ill older Canadians. Health Promotion International 12, 111 (1997)

40. D. Milam, M. Seif El-Nasr, R. Wakkary: Looking at the Interactive Narrative Experience through the Eyes of the Participants. Interactive Storytelling 96-107 (2008)
41. N. Montfort: Twisty Little Passages: an approach to interactive fiction. The MIT Press (2005)

42. L. Nacke, C.A. Lindley: Flow and immersion in first-person shooters: measuring the player's gameplay experience. Proceedings of the 2008 Conference on Future Play: Research, Play, Share, pp. 81-88. ACM, (2008)

43. T. Pellino, A. Tluczek, M. Collins, S. Trimborn, H. Norwick, Z. Engelke, J. Broad: Increasing self-efficacy through empowerment: preoperative education for orthopaedic patients. Orthopaedic Nursing 17, 48 (1998)

44. T. Pellino, A. Tluczek, M. Collins, S. Trimborn, H. Norwick, Z.K. Engelke, J. Broad: Increasing selfefficacy through empowerment: preoperative education for orthopaedic patients. Orthopaedic Nursing 17, 48 (1998)

45. M. Pibernik-Okanovic, M. Prasek, T. PoljicaninFilipovic, I. Pavlic-Renar, Z. Metelko: Effects of an empowerment-based psychosocial intervention on quality of life and metabolic control in type 2 diabetic patients. Patient education and counseling 52, 193-199 (2004)

46. J. Rodin, E. Langer: Long-term effects of a control-relevant intervention with the institutionalized aged. Journal of Personality and Social Psychology 35, 897-902 (1977)

47. D.H. Schunk: Modeling and attributional effects on children's achievement: A self-efficacy analysis. Journal of Educational Psychology 73, 93 (1981)

48. R. Schwarzer, M. Jerusalem: Generalized selfefficacy scale. Measures in health psychology: A user's portfolio. Causal and control beliefs 35-37 (1995)

49. P. Sweetser, P. Wyeth: GameFlow: a model for evaluating player enjoyment in games. Computers in Entertainment (CIE) 3, 3-3 (2005)

50. R. Thomas, J. Cahill, L. Santilli: Using an interactive computer game to increase skill and selfefficacy regarding safer sex negotiation: field test results. Health Education \& Behavior 24, 71 (1997)

51. H.A. van Dam, F. van der Horst, B. van den Borne, R. Ryckman, H. Crebolder: Provider-patient interaction in diabetes care: effects on patient self-care and outcomes: a systematic review. Patient education and counseling 51, 17-28 (2003)

52. N. Wallerstein: Powerlessness, empowerment, and health: implications for health promotion programs. American journal of health promotion (1992)

53. R.S. Weinberg, D. Gould, A. Jackson: Expectations and performance: An empirical test of Bandura's self-efficacy theory. Journal of Sport Psychology (1979) 